\title{
Osteosarcoma in Adolescents and Young Adults
}

\author{
Jun Ah Lee ${ }^{1}$, Jiwon Lim ${ }^{2}$, Hye Young Jin ${ }^{1}$, Meerim Park ${ }^{1}$, Hyeon Jin Park ${ }^{1}$, Jong Woong Park ${ }^{3}$, \\ June Hyuk Kim ${ }^{3}$, Hyun Guy Kang ${ }^{3}$ and Young-Joo Won ${ }^{2, *(D)}$ \\ 1 Center for Pediatric Cancer, Department of Pediatrics, Goyang 10408, Korea; junahlee@ncc.re.kr (J.A.L.); \\ hyjin@ncc.re.kr (H.Y.J.); meerim@ncc.re.kr (M.P.); hjpark@ncc.re.kr (H.J.P.) \\ 2 Division of Cancer Registration and Surveillance, Goyang 10408, Korea; mani98@ncc.re.kr \\ 3 Orthopedic Oncology Clinic, Center for Rare Cancer, National Cancer Center, Goyang 10408, Korea; \\ jwpark82@ncc.re.kr (J.W.P.); docjune@ncc.re.kr (J.H.K.); ostumor@ncc.re.kr (H.G.K.) \\ * Correspondence: astra67@ncc.re.kr; Tel.: +82-31-920-2015
}

Citation: Lee, J.A.; Lim, J.; Jin, H.Y.; Park, M.; Park, H.J.; Park, J.W.; Kim, J.H.; Kang, H.G.; Won, Y.-J. Osteosarcoma in Adolescents and Young Adults. Cells 2021, 10, 2684. https://doi.org/10.3390/cells10102684

Academic Editor: Takatsune Shimizu

Received: 5 August 2021

Accepted: 4 October 2021

Published: 7 October 2021

Publisher's Note: MDPI stays neutral with regard to jurisdictional claims in published maps and institutional affiliations.

Copyright: (c) 2021 by the authors. Licensee MDPI, Basel, Switzerland. This article is an open access article distributed under the terms and conditions of the Creative Commons Attribution (CC BY) license (https:// creativecommons.org/licenses/by/ $4.0 /)$.

\begin{abstract}
The epidemiology of osteosarcoma in adolescents and young adults (AYA) remains unclear. We aimed to assess and compare the clinical features of osteosarcoma between AYA and other age groups. We retrieved osteosarcoma cases diagnosed between 1999 and 2017 from the Korea Central Cancer Registry. We compared survival trends and clinical characteristics between AYA and other age groups. AYA comprised 43.3\% (1309/3022) of the osteosarcoma cases. Compared to other age groups, the male-to-female ratio was highest in AYA (1.61:1). The proportion of tumors located in an extremity was $80.3 \%$ in AYA, which was lower than in young children $(92.5 \%)$ or pubertal children $(93.8 \%)$ but higher than in adults $(55.7 \%)$ or the elderly $(47.5 \%)$. As for treatments, $71.2 \%$ of AYA received local treatment and systemic chemotherapy, and $28.8 \%$ received only local treatment (surgery: 261, radiotherapy: 9, surgery and radiotherapy: 5). The 5-year overall survival (OS) was lower in AYA (68\%) than in young children $(78 \%)$ or pubertal children $(73 \%)$ but higher than in adults (47\%) or the elderly (25\%). When AYA were divided into five subgroups by age, patients aged 15-19 years constituted the largest proportion $(45.4 \%, n=594)$. Additionally, the proportion of patients with a non-extremity tumor increased in an age-dependent manner, from $10.3 \%$ in AYA aged 15-19 years to 35.3\% in AYA aged 35-39 years. OS did not significantly differ among the different age subgroups of AYA. The clinical characteristics and OS of the AYA were more similar to those of children than to those of adults. There is a need for cooperation between pediatric and adult oncologists for effective osteosarcoma treatment in AYA.
\end{abstract}

Keywords: osteosarcoma; adolescents and young adults (AYA); Korea

\section{Introduction}

Osteosarcoma is the most common primary malignant bone tumor in children and adolescents [1]. The prognostic significance of age in osteosarcoma remains unclear [2-5]. Studies have dichotomized patients using specific age-based cut-off values, followed by a comparison of survival rates [2-5]. Data from the Surveillance, Epidemiology, and End Results (SEER) database showed that patients aged greater than 15 years have a lower 5-year relative survival than those aged less than 15 years [6]. The Children Oncology Group (COG) reported that patients with osteosarcoma aged greater than 18 years have a significantly increased risk of relapse and death [7]. Given that the age range of 15 to 18 years corresponds to the beginning or middle of the adolescent period [8], there is a need to determine whether the outcomes of osteosarcoma in adolescents and young adults (AYA) are inferior to those of children.

The US Adolescent and Young Adult Oncology Progress Review Group defined AYA patients with cancer as those diagnosed with cancer between the ages of 15 and 39 years [9]. AYA are in a transitional period between different phases of life, with distinct epidemiological, clinical, and biological characteristics [9]. There remains scarce research 
on cancers in AYA [10]; moreover, current knowledge regarding osteosarcoma has been obtained from retrospective studies and clinical trials conducted by pediatric cooperative groups [11]. However, given the wide age span across AYA, these patients can receive clinical care from pediatric or adult oncologists. Although the clinical characteristics and outcomes of AYA with osteosarcoma remain unclear, population-based cancer registries could yield important insights.

Therefore, we aimed to analyze and compare the clinical features of osteosarcoma between AYA and other age groups using epidemiological data obtained from the Korea Central Cancer Registry (KCCR).

\section{Materials and Methods}

\subsection{Data Sources}

The KCCR contains information obtained from the entire Korean population with cancer since 1999, including demographics, date of first diagnosis, primary site, morphology, diagnostic method, stage, and initial treatment. We applied the osteosarcoma definition provided by the International Classification of Diseases for Oncology, 3rd edition [12]. We extracted data regarding the incidence and survival of patients with osteosarcoma between 1999 and 2017. Data regarding mortality were obtained from Statistics Korea [13]. This study was approved by the institutional review board of the National Cancer Center (IRB No. NCC 2021-0064).

\subsection{Statistical Analyses}

Patients were age-grouped as follows: young children, $\leq 9$ years; pubertal children, 10-14 years; AYA, 15-39 years; adults, 40-64 years; and elderly individuals, $\geq 65$ years. We performed among-group comparisons of the incidence and clinical characteristics, including sex, diagnosis period (1999-2003, 2004-2008, 2009-2013, or 2014-2017), tumor location (extremity: upper, lower; axial: pelvis, spine, or elsewhere), SEER summary stage (since 2006) [14], and the first treatment course within 4 months of diagnosis.

Overall survival (OS) rates were calculated using the Kaplan-Meier method. OS comparisons among patients grouped according to clinical variables were performed using the log-rank test. A Cox proportional hazards model was used to estimate the effects of covariates on hazard rates. All statistical tests were two-tailed. Statistical significance was set at $p<0.05$. Statistical analyses were conducted using SAS software ver. 9.4 (SAS Institute Inc., Cary, NC, USA) and STATA software ver. 16 (StataCorp LLC, College Station, TX, USA).

\section{Results}

\subsection{Osteosarcoma in the KCCR Database}

Between 1999 and 2017, there were 3022 osteosarcoma cases in the national cancer registry database. The median age at osteosarcoma diagnosis was 21 years, with the teenage group showing the highest occurrence (Figure 1 and Table 1 ). Overall, there were more male patients (male-to-female ratio $=1.27: 1)($ Table 1$)$. In most cases $(2294$ cases, $75.9 \%)$, the primary tumor site was an extremity.

Since 2006, the KCCR has included information regarding disease extent from 1972 cases. Among them, the disease extent at diagnosis was unknown and metastases in $413(21.0 \%)$ and $648(32.9 \%)$ cases, respectively. Treatment information was available for 2206 patients, with $2146(97.3 \%)$ patients having undergone surgery. Multimodal treatment comprising both surgery and chemotherapy was administered to 1452 (65.8\%) patients. 


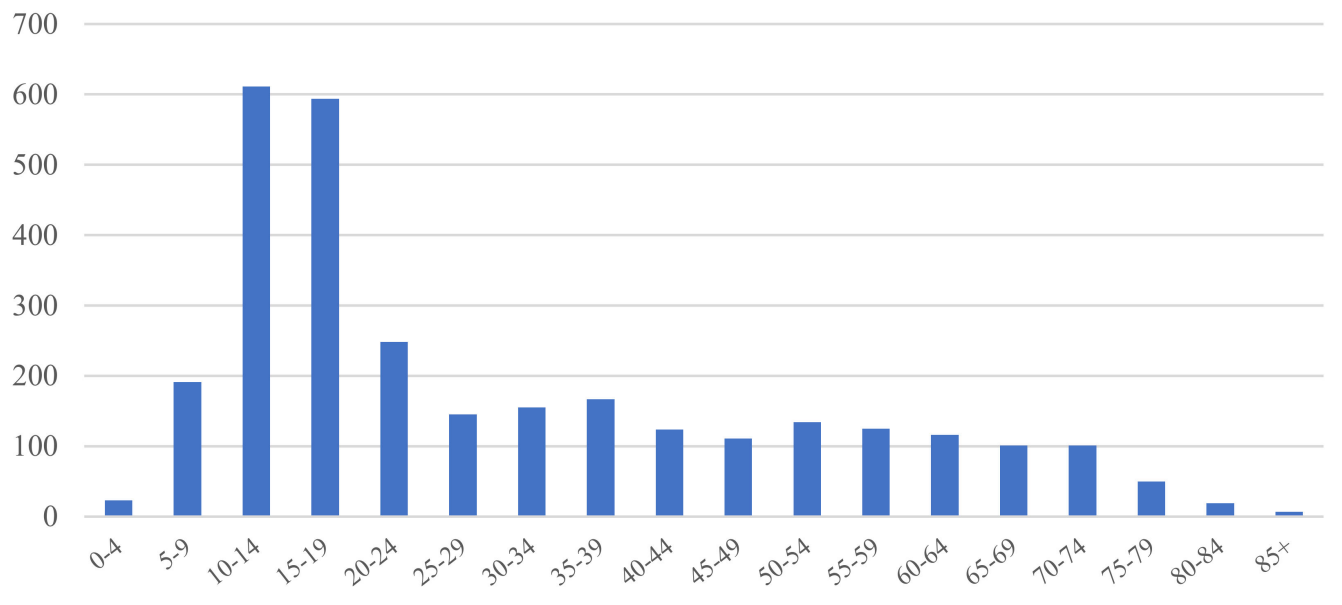

Figure 1. Age distribution of patients with osteosarcoma.

Table 1. Characteristics of osteosarcoma cases diagnosed between 1999 and 2017.

\begin{tabular}{|c|c|c|c|}
\hline \multicolumn{2}{|c|}{ Characteristics } & \multirow{2}{*}{$\begin{array}{c}\text { Number }(n=\mathbf{3 0 2 2}) \\
1689\end{array}$} & \multirow{2}{*}{$\begin{array}{c}\% \\
55.89\end{array}$} \\
\hline & Male & & \\
\hline Sex & female & 1333 & 44.11 \\
\hline & Male to female ratio & & 1.27 \\
\hline \multirow{3}{*}{ Location } & Extremity (upper, lower) & 2294 & 75.91 \\
\hline & Axial (pelvis, spine) & 404 & 13.37 \\
\hline & Elsewhere & 324 & 10.72 \\
\hline \multirow{5}{*}{ Age group } & Young children ( $\leq 9$ years) & 214 & 7.08 \\
\hline & $\begin{array}{c}\text { Pubertal children (10-14 } \\
\text { years) }\end{array}$ & 611 & 20.22 \\
\hline & AYA (15-39 years) & 1309 & 43.32 \\
\hline & Adults (40-64 years) & 610 & 20.19 \\
\hline & Elderly ( $\geq 65$ years) & 278 & 9.20 \\
\hline \multirow{4}{*}{ Diagnostic period } & 1999-2003 & 764 & 25.28 \\
\hline & 2004-2008 & 764 & 25.28 \\
\hline & 2009-2013 & 812 & 26.87 \\
\hline & 2014-2017 & 682 & 22.57 \\
\hline \multirow{3}{*}{$\begin{array}{c}\text { Extent of } \\
\text { disease } \\
(n=1972, \text { since 2006) }\end{array}$} & Localized & 911 & 46.20 \\
\hline & Metastasis & 648 & 32.86 \\
\hline & Unknown & 413 & 20.94 \\
\hline \multirow{7}{*}{ Treatment } & Surgery only & 650 & 21.51 \\
\hline & RT only & 26 & 0.86 \\
\hline & Surgery + RT & 44 & 1.46 \\
\hline & Surgery + CTx & 1360 & 45.00 \\
\hline & $\mathrm{CTx}+\mathrm{RT}$ & 34 & 1.13 \\
\hline & Surgery + CTx + RT & 92 & 3.04 \\
\hline & Unknown & 816 & 27.00 \\
\hline
\end{tabular}

\subsection{Comparisons of AYA Patients with Other Age Groups}

Some typical clinical characteristics of osteosarcoma, including an extremity being the primary tumor site and male predominance, were evident in young children, pubertal children, and AYA. Contrastingly, in adults and elderly individuals, females comprised half of the cases; moreover, there was a higher proportion of patients with a non-extremity tumor location or metastasis at diagnosis (Table 2). There were differences in the administered treatment modalities among the age groups, with adults and elderly individuals having lower rates of systemic chemotherapy use. The proportions of patients who received only local treatment (surgery or radiotherapy) were $43.6 \%(205 / 470)$ and $73.5 \%(164 / 223)$ in 
adults and elderly individuals, respectively. The proportions of patients who received multimodal treatment (local treatment and systemic chemotherapy) were $56.4 \%(265 / 470)$ and $26.5 \%(59 / 223)$ among adults and elderly individuals, respectively. Contrastingly, 113 young children (83.7\%), 368 pubertal children (87.2\%), and 681 AYA (71.2\%) received local treatment and systemic chemotherapy (Table 2).

Table 2. Comparison of clinical characteristics between the age groups.

\begin{tabular}{|c|c|c|c|c|c|c|c|}
\hline & \multirow[b]{2}{*}{ Variables } & \multicolumn{6}{|c|}{ Age } \\
\hline & & $\begin{array}{l}\text { Young } \\
\text { Children } \\
(n=214)\end{array}$ & $\begin{array}{l}\text { Pubertal } \\
\text { Children } \\
(n=611)\end{array}$ & $\begin{array}{c}\text { AYA } \\
(n=1309)\end{array}$ & $\begin{array}{l}\text { Adults } \\
(n=610)\end{array}$ & $\begin{array}{c}\text { Elderly } \\
(n=278)\end{array}$ & $p$-Value \\
\hline \multirow{3}{*}{ Sex } & Male & 123 & 327 & 808 & 302 & 129 & \multirow{3}{*}{$<0.0001$} \\
\hline & Female & 91 & 284 & 501 & 308 & 149 & \\
\hline & Male to female ratio & 1.35 & 1.15 & 1.61 & 0.98 & 0.87 & \\
\hline \multirow{3}{*}{ Location } & Extremity & 198 & 573 & 1051 & 340 & 132 & \multirow{3}{*}{$<0.0001$} \\
\hline & Axial & 2 & 23 & 138 & 151 & 90 & \\
\hline & Elsewhere & 14 & 15 & 120 & 119 & 56 & \\
\hline \multirow{3}{*}{$\begin{array}{c}\text { Extent of } \\
\text { disease } \\
\text { (since 2006) }\end{array}$} & Localized & 56 & 175 & 396 & 197 & 87 & \multirow{3}{*}{0.0010} \\
\hline & Metastasis & 35 & 115 & 245 & 161 & 92 & \\
\hline & Unknown & 33 & 103 & 159 & 82 & 36 & \\
\hline \multirow{7}{*}{ Treatment } & Surgery only & 22 & 51 & 261 & 185 & 131 & \multirow{7}{*}{$<0.0001$} \\
\hline & RT only & 0 & 2 & 9 & 4 & 11 & \\
\hline & Surgery + RT & 0 & 1 & 5 & 16 & 22 & \\
\hline & Surgery + CTx & 109 & 356 & 633 & 214 & 48 & \\
\hline & $\mathrm{CTx}+\mathrm{RT}$ & 1 & 4 & 11 & 16 & 2 & \\
\hline & Surgery + CTx + RT & 3 & 8 & 37 & 35 & 9 & \\
\hline & Unknown & 79 & 189 & 353 & 140 & 55 & \\
\hline
\end{tabular}

AYA comprised 43.3\% (1309) of the patients with osteosarcoma registered in the KCCR. The male-to-female ratio was higher in the AYA group (1.61:1) than in the other age groups. The proportion of extremity tumors was lower in AYA (80.3\%) than in young children $(92.5 \%)$ or pubertal children $(93.8 \%)$, but higher than in adults $(55.7 \%)$ or elderly individuals $(47.5 \%)$. The proportion of patients with metastases at diagnosis in AYA was lower than that in adults or elderly individuals, but similar to that in younger patients. The proportion of patients who received multimodal treatment was lower in AYA $(71.2 \%)$ than in young $(83.7 \%)$ and pubertal children (87.2\%). Moreover, the proportion of patients who only received local treatment was higher in AYA $(28.8 \%)$ than in young children $(16.3 \%)$ and pubertal children (12.8\%) (Table 2).

The 5-year OS rates of AYA patients were similar between 1999 and 2013 (Figure 2).

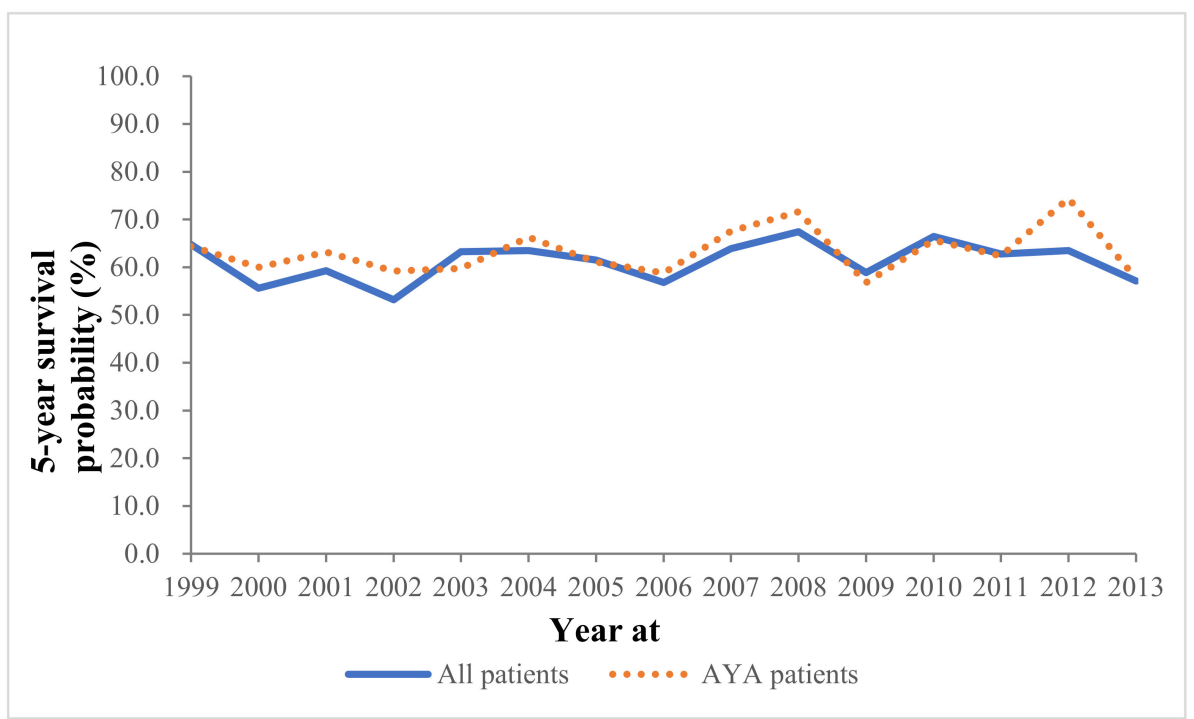

Figure 2. The 5-year overall survival trend of patients with osteosarcoma. 
Survival analysis of 3017 patients revealed a 5 -year OS rate of $61 \%$. OS was inversely correlated with age and abruptly decreased in adults (46\%) and elderly individuals (25\%) (Table 3). Univariate and multivariate analyses revealed that tumor location, presence of metastasis at diagnosis, and age were prognostic factors (Table 3).

Table 3. The overall survival and hazard ratio of osteosarcoma according to clinical variables.

\begin{tabular}{|c|c|c|c|c|c|c|c|c|}
\hline \multirow{2}{*}{\multicolumn{2}{|c|}{ Variables }} & \multirow{4}{*}{$\begin{array}{l}\text { No. } \\
1684 \\
1333 \\
\end{array}$} & \multirow{4}{*}{$\begin{array}{c}\begin{array}{c}\text { Median } \\
\text { Survival Time } \\
\text { (Month) }\end{array} \\
- \\
-\end{array}$} & \multirow{4}{*}{$\begin{array}{c}\begin{array}{c}\text { 5-Year } \\
\text { Survival (\%) } \\
\text { (CI) }\end{array} \\
62(59-64) \\
62(59-64)\end{array}$} & \multicolumn{2}{|c|}{ Univariate } & \multicolumn{2}{|c|}{ Multivariate } \\
\hline & & & & & \multirow{3}{*}{$\begin{array}{c}\text { HR } \\
\text { Reference } \\
1.01(0.89-1.13)\end{array}$} & \multirow{3}{*}{$\frac{p \text {-Value }}{0.9198}$} & \multirow{3}{*}{$\begin{array}{c}\text { HR } \\
\text { Reference } \\
0.92(0.81-1.03)\end{array}$} & \multirow{3}{*}{$\frac{p \text {-Value }}{0.1549}$} \\
\hline & Male & & & & & & & \\
\hline Sex & Female & & & & & & & \\
\hline \multirow{3}{*}{ Location } & Extremity & 2291 & - & $68(66-70)$ & Reference & \multirow[t]{3}{*}{$<0.0001$} & Reference & \multirow[t]{3}{*}{$<0.0001$} \\
\hline & Axial & 403 & 25 & $36(31-41)$ & $2.72(2.33-3.17)$ & & $0.91(1.62-2.24)$ & \\
\hline & Elsewhere & 323 & 54 & $49(43-55)$ & $1.77(1.48-2.12)$ & & $1.31(1.09-1.58)$ & \\
\hline \multirow{3}{*}{$\begin{array}{c}\text { Extent of } \\
\text { disease } \\
\text { (since 2006) }\end{array}$} & Localized & 910 & - & $73(69-76)$ & Reference & \multirow[t]{3}{*}{$<0.0001$} & Reference & \multirow[t]{3}{*}{$<0.0001$} \\
\hline & Metastasis & 644 & 41 & $44(40-48)$ & $2.60(2.19-3.10)$ & & $2.40(2.03-2.84)$ & \\
\hline & Unknown & 413 & - & $71(66-75)$ & $0.98(0.78-1.24)$ & & $1.57(1.34-1.83)$ & \\
\hline \multirow{5}{*}{ Age group } & Young children & 214 & - & $78(71-83)$ & Reference & \multirow[t]{5}{*}{$<0.0001$} & Reference & \multirow[t]{5}{*}{$<0.0001$} \\
\hline & Pubertal children & 610 & - & 73 (70-77) & $1.24(0.90-1.70)$ & & $1.22(0.89-1.67)$ & \\
\hline & AYA & 1307 & - & $68(65-71)$ & 1.47 (1.09-1.98) & & $1.35(1.00-1.82)$ & \\
\hline & Adults & 608 & 44 & $47(43-51)$ & $3.06(2.64-4.16)$ & & $2.55(1.87-3.47)$ & \\
\hline & Elderly & 278 & 20 & $25(20-31)$ & $5.88(4.28-8.08)$ & & $4.69(3.39-6.49)$ & \\
\hline
\end{tabular}

Further, the OS rate in AYA was lower than that in young children or pubertal children, but higher than that in adults or elderly individuals. There was an approximately $5 \%$ difference in the OS rate among young children, pubertal children, and AYA (Table 3). Contrastingly, there was an approximately $20 \%$ difference in the OS rate among AYA, adults, and elderly individuals (68\%, $47 \%$, and $25 \%$, respectively) (Table 3 ). AYA patients with extremity tumors showed a similar survival to young children and pubertal children (Figure 3A). The 5-year OS rates of patients with extremity tumors according to age were as follows: $77.9 \%$, young children; $74.0 \%$, pubertal children; $70.9 \%$, AYA; $56.5 \%$, adults; and $31.6 \%$, the elderly. Additionally, the OS rate of AYA with axial tumors was lower than that of pubertal children $(53.8 \%$ vs. $67.0 \%$, Figure $3 \mathrm{~B})$.

\subsection{Age-Based Subgroups Analysis of AYA Patients}

Among five age-based subgroups of the AYA group, patients aged 15-19 years comprised the largest proportion $(45.4 \%, n=594)$. Moreover, there were among-subgroup differences in the clinical characteristics (Table 4). Patients aged 15-19 and 20-24 years showed male predominance, with male-to-female ratios of 1.9 (389 males, 205 females) and 2.3 (172 males and 76 females), respectively. Across all age subgroups, most tumors were located in the extremities. Further, there was an age-dependent increase in the proportion of non-extremity tumors as follows: $10.3 \%, 15-19$ years; $16.5 \%$, $20-24$ years; $27.6 \%$, $25-29$ years; $36.8 \%$, 30-34 years; and 35.3\%, 35-39 years. There was no significant amonggroup difference in the OS rate $(p=0.08$, Figure 4$)$. However, patients aged 20-24 years showed the best 5 -year OS rate $(74.4 \%)$. Further, the OS rate in patients aged 15-19 years was slightly lower than that in patients aged 20-29 years. 
(A)

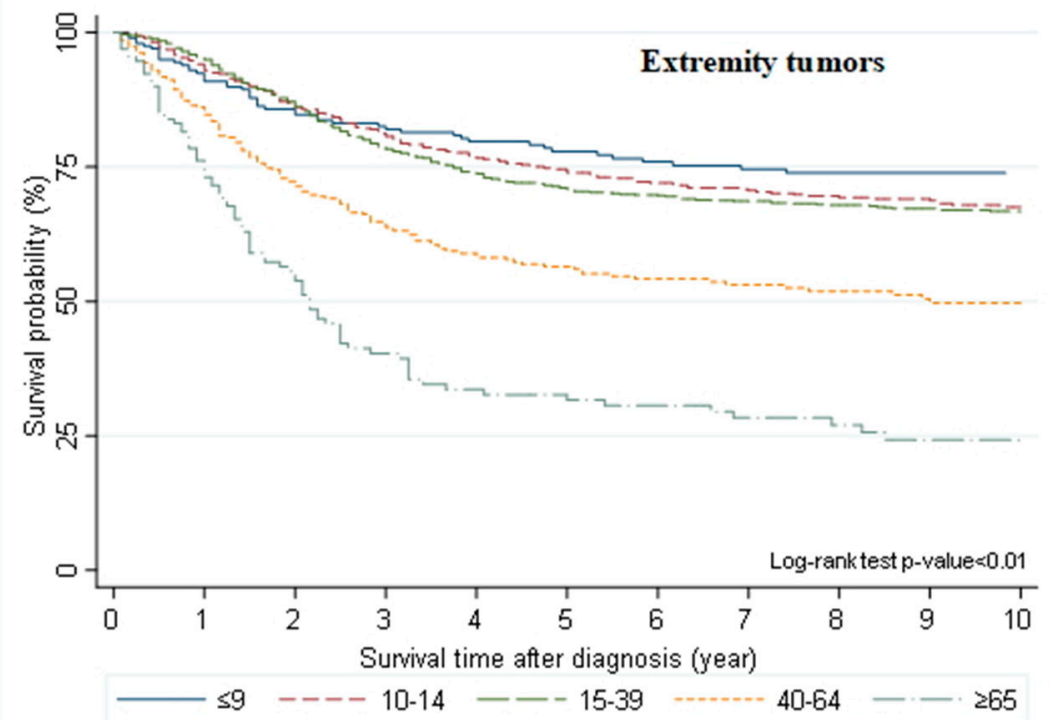

(B)

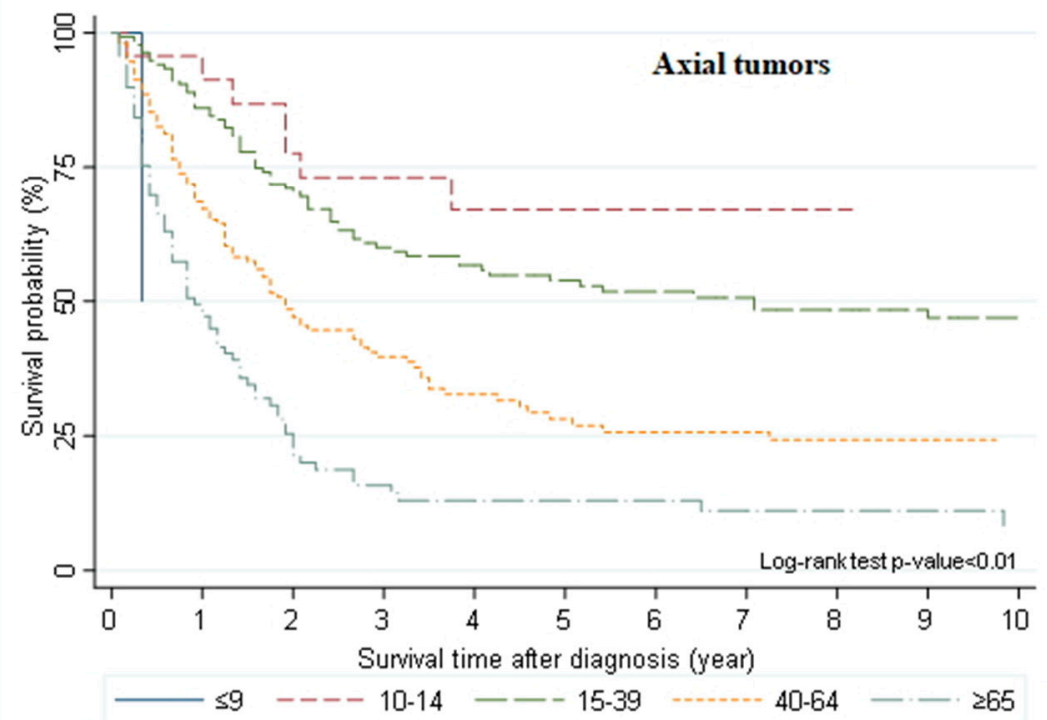

Figure 3. Overall survival of patients with osteosarcoma according to age and tumor site. (A) Extremity tumors, (B) Axial tumors.

Table 4. Comparison of clinical characteristics among AYA age subgroups.

\begin{tabular}{|c|c|c|c|c|c|c|c|}
\hline \multirow{2}{*}{\multicolumn{2}{|c|}{ Variables }} & \multicolumn{6}{|c|}{ Age (Years) } \\
\hline & & $\begin{array}{c}15-19 \\
(n=594)\end{array}$ & $\begin{array}{c}20-24 \\
(n=248)\end{array}$ & $\begin{array}{c}25-29 \\
(n=145)\end{array}$ & $\begin{array}{c}30-34 \\
(n=155)\end{array}$ & $\begin{array}{c}35-39 \\
(n=167)\end{array}$ & $p$-Value \\
\hline \multirow{3}{*}{ Sex } & Male & 389 & 172 & 77 & 78 & 92 & \multirow{3}{*}{$<0001$} \\
\hline & Female & 205 & 76 & 68 & 77 & 75 & \\
\hline & Extremity & 533 & 207 & 105 & 98 & 108 & \\
\hline \multirow[t]{2}{*}{ Location } & Axial & 43 & 25 & 13 & 24 & 33 & \multirow[t]{2}{*}{$<0001$} \\
\hline & Elsewhere & 18 & 16 & 27 & 33 & 26 & \\
\hline \multirow{3}{*}{$\begin{array}{l}\text { Extent of } \\
\text { disease } \\
\text { (since 2006) }\end{array}$} & Localized & 171 & 71 & 49 & 51 & 54 & \multirow{3}{*}{0.7419} \\
\hline & Metastasis & 110 & 45 & 30 & 27 & 33 & \\
\hline & Unknown & 75 & 29 & 12 & 25 & 18 & \\
\hline
\end{tabular}




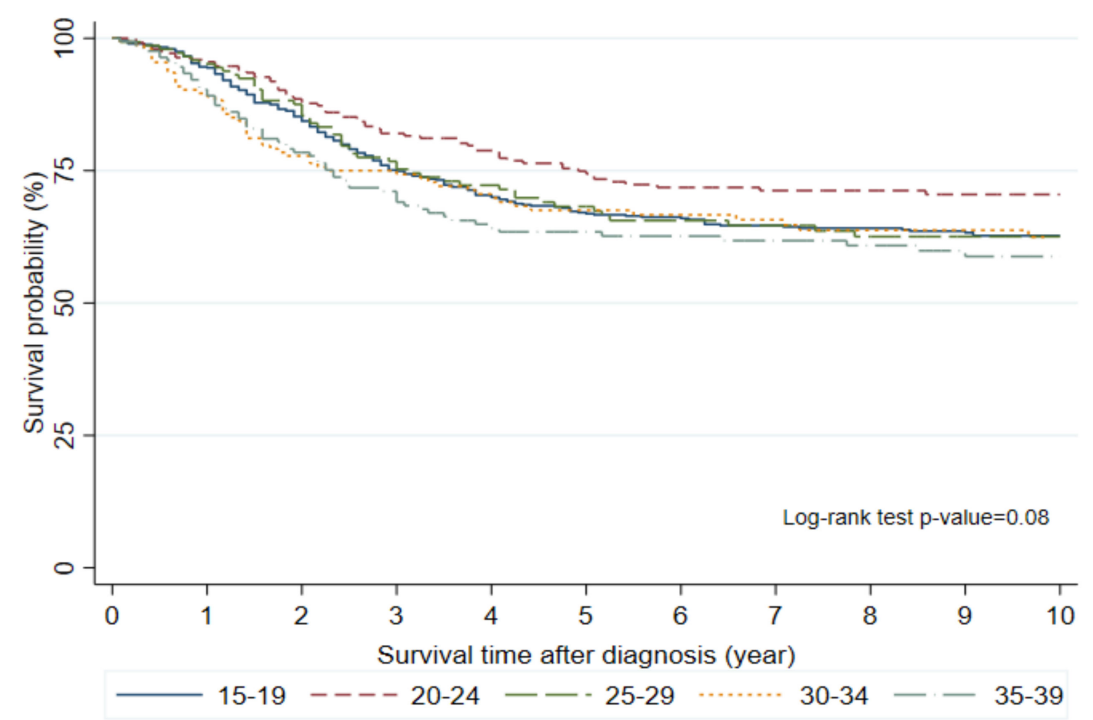

Figure 4. Overall survival of AYA by age subgroups.

\section{Discussion}

To our knowledge, this is the first study to report epidemiologic data regarding osteosarcoma in Korean AYA. AYA patients accounted for $43.3 \%$ of osteosarcoma cases registered in the KCCR from 1999 to 2017. The 5-year OS rate was 68\% in Korean AYA patients with osteosarcoma, which fell in between the OS rates of children and adults. Among the AYA, there were slight age-based differences in the clinical characteristics and outcomes. For example, there was evident male predominance in patients aged $<25$ years; further, there was an increased proportion of non-extremity tumors in patients aged $>30$ years. There were no significant among-subgroup differences in the OS rates.

The clinical characteristics and survival rates of Korean AYA patients with osteosarcoma were more similar to those of children than those of adults. AYA have worse outcomes than children in various chemosensitive cancers [6]. This could be attributed to multiple factors, including delayed diagnoses, different tumor biology, decreased participation in clinical trials, worse compliance with chemotherapy schedules, distinct chemotherapy metabolism, and increased toxicity leading to delayed chemotherapy [15]. Several studies have reported that AYA patients with osteosarcoma have significantly worse survival rates than children [6,7]. For example, a COG study on osteosarcoma reported a significantly increased risk of relapse or death in AYA aged 18-30 years [7]. The EURAMOS study also reported that adolescents (males: 13-17 years; females: $12-16$ years) and adults (males: $\geq 18$ years; females: $\geq 17$ years) had inferior event-free survival than had children (males: 0-12 years; females: 0-11 years) [16]. Further, the US SEER showed that the 5-year relative survival rate was lower in AYA (65.4\%) than in children $(<15$ years; $75.6 \%)$ [6]. The survival patterns of Korean AYA patients with osteosarcoma were consistent with the US SEER data [6], falling between the survival rates of children and adults. Moreover, a study of the Japanese Bone and Soft Tissue Tumor registry reported similar survival rates in AYA (75.2\%) and children (75.7\%) [17]. However, Japanese AYA patients receive the same chemotherapy as children [17], suggesting that the survival rates for AYA could be improved to those in children by administration of the same meticulous multidisciplinary treatment.

Age-based subgroup analysis of the AYA patients revealed that the survival rate in patients aged 15-19-years was slightly lower than that in young children or pubertal children. Although there was no significant among-group difference in the survival rates, the 20-24-year-old subgroup showed the highest survival rate, which was similar to that in young and pubertal children. The reasons underlying these findings remain unclear. There were no differences in treatment modalities among AYA aged 15-19 years, children ( $<15$ years), and AYA aged $>20$ years. The treatment compliance of AYA aged 15-19 years 
might be similar to that of children given the strong involvement of the parents or guardians in cancer treatment. Park et al. reported similar survival-related findings in Korean AYA patients with cancer; specifically, patients aged 15-19 years had lower survival rates than patients aged 20-39 years [18]. Therefore, there could be differences in tumor biology or drug metabolism between adolescents and young adults. There is a need for further studies to elucidate the reasons why patients aged 15-19 years have worse outcomes than those aged $20-24$ years.

There were similar treatment modalities and survival rates of Korean AYA patients with osteosarcoma from 1999 to 2017. Unfortunately, specific treatment-related information, including the chemotherapy regimen or surgery extent, is unavailable in the KCCR database. However, the Korean Society of Pediatric Hematology and Oncology reported that $>90 \%$ of patients with extremity tumors undergo limb salvage surgery [19]. Furthermore, systemic chemotherapy combining two to four agents is administered and is often postoperatively switched according to the histological response to preoperative chemotherapy [19]. Further, our findings indicated that surgery remained the standard for local treatment of osteosarcoma during the 19 year period. Additionally, the indications for radiotherapy are limited to osteosarcoma $[19,20]$. AYA patients who only received radiotherapy $(2.1 \%$ [20/956]) had tumors located at sites where complete surgery was not feasible. Although information regarding the surgical margins was unavailable, $42(4.4 \%)$ patients who underwent surgery and radiotherapy might have undergone incomplete surgery, with either a macroscopic or microscopic residual tumor. Excluding thyroid cancer, the 5-year relative survival rates of Korean AYA improved by 23.0\% between 1993 and 1995 and 2012 and 2016 [18]. However, the survival rates of Korean patients with osteosarcoma, including AYA, were similar throughout the study period. This is consistent with previous clinical reports, indicating that the survival rates of patients with osteosarcoma have not changed over the past few decades [21].

This study has several limitations resulting from the nature of KCCR data. For example, the KCCR database lacks information regarding the previous medical history or comorbidities. Information on disease extent at diagnosis only became available after 2006; moreover, there remains no information regarding tumor size, tumor grade, chemotherapy regimen, and histopathological response to preoperative chemotherapy. Moreover, the registered treatment-related information only included the treatments administered during the first 4 post-diagnosis months. Therefore, the prognostic significance of these clinical variables should be considered only within the context of the currently available data.

In conclusion, the survival rate of Korean AYA patients with osteosarcoma was lower than that of children. Further, the clinical characteristics and outcomes slightly differed across age subgroups of AYA. Our findings indicate the need for collaboration between pediatric and adult oncologists to elucidate the biological characteristics and improve the outcomes of AYA with osteosarcoma.

Author Contributions: Conceptualization, Y.-J.W. and J.A.L.; Methodology, Y.-J.W. and J.L.; Formal analysis, J.L.; Data curation, J.L. and Y.-J.W.; Writing-original draft preparation, J.A.L., J.L., and Y.-J.W.; Writing—review and editing, J.A.L., J.L., H.Y.J., M.P., H.J.P., J.W.P., J.H.K., H.G.K., and Y.-J.W.; Visualization, J.L.; Supervision, Y.-J.W.; Funding acquisition, Y.-J.W. All authors have read and agreed to the published version of the manuscript.

Funding: This research was funded by the National Cancer Center of the Republic of Korea, research grant (No. 1910132-3).

Institutional Review Board Statement: The study was conducted according to the guidelines of the Declaration of Helsinki and approved by the Institutional Review Board of National Cancer Center (IRB No. NCC 2021-0064).

Conflicts of Interest: The authors declare no conflict of interest. 


\section{References}

1. Longhi, A.; Errani, C.; De Paolis, M.; Mercuri, M.; Bacci, G. Primary Bone Osteosarcoma in the Pediatric Age: State of the Art. Cancer Treat. Rev. 2006, 32, 423-436. [CrossRef] [PubMed]

2. Ferrari, S.; Bertoni, F.; Mercuri, M.; Picci, P.; Giacomini, S.; Longhi, A.; Bacci, G. Predictive Factors of Disease-Free Survival for Non-Metastatic Osteosarcoma of the Extremity: An Analysis of 300 Patients Treated at the Rizzoli Institute. Ann. Oncol. 2001, 12, 1145-1150. [CrossRef] [PubMed]

3. Bacci, G.; Longhi, A.; Versari, M.; Mercuri, M.; Briccoli, A.; Picci, P. Prognostic Factors for Osteosarcoma of the Extremity Treated with Neoadjuvant Chemotherapy: 15-Year Experience in 789 Patients Treated at a Single Institution. Cancer 2006, 106, 1154-1161. [CrossRef] [PubMed]

4. Bacci, G.; Longhi, A.; Bertoni, F.; Bacchini, P.; Ruggeri, P.; Versari, M.; Picci, P. Primary High-Grade Osteosarcoma: Comparison Between Preadolescent and Older Patients. J. Pediatr. Hematol. Oncol. 2005, 27, 129-134. [CrossRef] [PubMed]

5. Meyers, P.A.; Heller, G.; Healey, J.; Huvos, A.; Lane, J.; Marcove, R.; Applewhite, A.; Vlamis, V.; Rosen, G. Chemotherapy for Nonmetastatic Osteogenic Sarcoma: The Memorial Sloan-Kettering Experience. J. Clin. Oncol. 1992, 10, 5-15. [CrossRef] [PubMed]

6. Keegan, T.H.; Ries, L.A.; Barr, R.D.; Geiger, A.M.; Dahlke, D.V.; Pollock, B.H.; Bleyer, W.A.; National Cancer Institute Next Steps for Adolescent and Young Adult Oncology Epidemiology Working Group. Comparison of Cancer Survival Trends in the United States of Adolescents and Young Adults with Those in Children and Older Adults. Cancer 2016, 122, 1009-1016. [CrossRef] [PubMed]

7. Janeway, K.A.; Barkauskas, D.A.; Krailo, M.D.; Meyers, P.A.; Schwartz, C.L.; Ebb, D.H.; Seibel, N.L.; Grier, H.E.; Gorlick, R.; Marina, N. Outcome for Adolescent and Young Adult Patients with Osteosarcoma: A Report from the Children's Oncology Group. Cancer 2012, 118, 4597-4605. [CrossRef] [PubMed]

8. Pollock, B.H.; Birch, J.M. Registration and Classification of Adolescent and Young Adult Cancer Cases. Pediatr. Blood Cancer 2008, 50, 1090-1093. [CrossRef] [PubMed]

9. US Department of Health and Human Services; National Institutes of Health; National Cancer Institute; LIVESTRONG Young Adult Alliance. Closing the Gap: Research and Care Imperatives for Adolescents and Young Adults with Cancer; Report of the Adolescent and Young Adult Oncology Progress Review Group; NIH Pub. No. 06-6067; National Institutes of Health: Bethesda, MD, USA, 2006.

10. Children's Oncology Group; SEER Program (National Cancer Institute [U.S.]). Cancer Epidemiology in Older Adolescents and Young Adults 15 to 29 Years of Age, Including SEER Incidence and Survival: 1975-2000; U.S. Department of Health and Human Services, National Institutes of Health, National Cancer Institute: Bethesda, MD, USA, 2006; p. 205.

11. Herzog, C.E. Overview of Sarcomas in the Adolescent and Young Adult Population. J. Pediatr. Hematol. Oncol. 2005, 27, 215-218. [CrossRef] [PubMed]

12. World Health Organization. International Classification of Diseases for Oncology, 3rd ed.; Fritz, A.P., Percy, C., Jack, A., Shanmugaratnam, K., Sobin, L., Parkin, D.M., Whelan, S., Eds.; World Health Organization: Geneva, Switzerland, 2000.

13. Daejeon: Statistics Korea. 2018. Available online: http:// kosis.kr. (accessed on 28 February 2020).

14. Young, J.L., Jr.; Roffers, S.; Ries, L.; Fritz, A.; Hurlbut, A.A. SEER Summary Staging Manual -2000: Codes and Coding Instructions; National Cancer Institute, National Institutes of Health: Bethesda, MD, USA, 2001.

15. Coccia, P.F. Overview of Adolescent and Young Adult Oncology. J. Oncol. Pract. 2019, 15, 235-237. [CrossRef] [PubMed]

16. Smeland, S.; Bielack, S.S.; Whelan, J.; Bernstein, M.; Hogendoorn, P.; Krailo, M.D.; Gorlick, R.; Janeway, K.A.; Ingleby, F.C.; Anninga, J.; et al. Survival and prognosis with osteosarcoma: Outcomes in more than 2000 patients in the EURAMOS-1 (European and American Osteosarcoma Study) cohort. Eur. J. Cancer 2019, 109, 36-50. [CrossRef] [PubMed]

17. Fukushima, T.; Ogura, K.; Akiyama, T.; Takeshita, K.; Kawai, A. Descriptive Epidemiology and Outcomes of Bone Sarcomas in Adolescent and Young Adult Patients in Japan. BMC Musculoskelet. Disord. 2018, 19, 297. [CrossRef] [PubMed]

18. Park, M.; Lim, J.; Lee, J.A.; Park, B.K.; Jung, K.W.; Won, Y.J.; Park, H.J. Cancer Incidence and Survival Among Adolescents and Young Adults in Korea: An Update for 2016. Cancer Res. Treat. 2021, 53, 32-44. [CrossRef] [PubMed]

19. Lee, J.A. Osteosarcoma in Korean Children and Adolescents. Korean J. Pediatr. 2015, 58, 123-128. [CrossRef] [PubMed]

20. Casali, P.G.; Bielack, S.; Abecassis, N.; Aro, H.; Bauer, S.; Biagini, R.; Bonvalot, S.; Boukovinas, I.; Bovee, J.V.M.G.; Brennan, B.; et al. Bone sarcomas: ESMO-PaedCan-EURACAN Clinical Practice Guidelines for diagnosis, treatment and follow-up. Ann. Oncol. 2018, 29, iv79-iv95. [CrossRef] [PubMed]

21. Bacci, G.; Forni, C.; Ferrari, S.; Longhi, A.; Bertoni, F.; Mercuri, M.; Donati, D.; Capanna, R.; Bernini, G.; Briccoli, A.; et al. Neoadjuvant Chemotherapy for Osteosarcoma of the Extremity: Intensification of Preoperative Treatment Does Not Increase the Rate of Good Histologic Response to the Primary Tumor or Improve the Final Outcome. J. Pediatr. Hematol. Oncol. 2003, 25, 845-853. [CrossRef] [PubMed] 